\title{
Prevention and Control of Japanese Encephalitis Viruses: A Challenged Issue
}

\author{
Somsak Pantuwatana ${ }^{1}$ and Matti Sallberg 2 \\ ${ }^{1}$ Burapha University, Bangsaen, Chon Buri, \\ ${ }^{2}$ Karolinska Institutet, Stockholm \\ 1Thailand \\ 2Sweden
}

\section{Introduction}

Encephalitis caused by Japanese encephalitis virus (JEV) is a leading cause of viral encephalitis of children less than 15 years old in Asia including Thailand. The virus is transmitted to human by several species of culicine mosquitoes including Culex tritaeniorhynchus, Culex gelidus, and Culex vishnui. The natural cycle occurs as a zoonotic cycle of which either pigs or birds serve as vertebrate amplifying host and man appears to be accidental hosts. In addition to human disease, JEV produces abortion and neonatal death in pigs and death in horses, which are economically important in the area where Japanese encephalitis occurs. Currently the specific drug for treatment of Japanese encephalitis is not available. The promising strategy for the prevention of this disease is vaccination together with efficient mosquito control, protection of the amplifying hosts, and prevention human from mosquito biting. Thus, the prevention and control of this disease is a challenged issue. The development of a vaccine that would induce rapid protection in people and animals is currently remained as an important issue. New generation of safe chimeric viruses that are unable to infect mosquitoes is currently ongoing in the development and preclinical studies. This would be a major step toward production of live-attenuated vaccine that is safer for the environment and would minimize the risk for vaccine-born outbreaks as reported in 1970s for TC-83 vaccine. However, additional efficacy trials in nonhuman primates are required to confirm the protective response for some of the candidates and for initiation of potential clinical trials. Some of the recent experimental data indicates that the immune response against Venezuelan Equine Encephalitis virus (VEEV) needed to control the brain infection may differ from the one required to control the peripheral infection. Therefore, vaccines that protect against the natural infection may differ in the future from those that are supposed to protect against high-dose air-borne challenge and may be more attenuated. Our group is also trying to use the most recent pathogenesis data to design a therapeutic vaccine that would reverse already established encephalitis and help clear the virus from the brain.

Plasmid DNA-based vaccination strategies have become an active area of research over the past decade due to their potential to produce safer and cheaper vaccines. These vaccines could be delivered to recipients by intra-muscular (IM) injection or intra-dermal (ID) administration using a gene gun. IM inoculation of plasmid DNA vaccines to mice induces 
predominantly $\mathrm{T}$ helper 1 (Th1) immune responses, while $\mathrm{T}$ helper 2 (Th2) type immune responses are generated following the ID delivery. The isotypes of antibodies and the types of cytokines induced by the two methods differ and this could have bearing on the efficacy of the vaccine candidate.

Attempts have been made to construct the plasmid DNA vaccine against JEV by trying to include JEV $e$ gene in the plasmid DNA. It has been shown that these plasmids are capable of synthesizing JEV premembrane (prM) and E proteins, which have been evaluated in mice. Both forms of $\mathrm{E}$ protein however generated JEV neutralizing antibodies that provided significant protection to mice against lethal JEV challenge.

In pre-clinical studies, after evaluation in rodent models, nonhuman primates are usually the models of choice as they provide a robust system for evaluation of vaccine candidates. The Old World monkeys have predominantly been used in these types of studies with rhesus (Macaca mulatta) and cynomolgus (Macaca fascicularis) monkeys being most popularly used for evaluation of vaccine candidates against various infectious diseases, including those caused by Flaviviruses. It has been shown that the immunogenicity of premembraneenvelop proteins (pMEa and pMEs) delivered intramuscularly (IM) or intradermally (ID) in rhesus monkeys resulted in the DNA immunization induced protective levels of JEV neutralizing antibodies and generated robust memory that led to a rapid and sustained anamnestic response in monkeys sham challenged with mouse brain-grown, formaldehyde inactivated commercial vaccine. Several JEV proteins were evaluated in the DNA vaccine modality for their ability to induce protective immunity in the murine system. These include plasmids could express non-structural protein 1 (NS1), E or prM and E proteins of JEV. It was shown that variable degree of efficacy in murine model systems with plasmids expressing prM and $\mathrm{E}$ proteins conferring high degree of protection of mice against lethal JEV challenge, largely due to their ability to induce JEV neutralizing antibodies. Two plasmids could express prM protein along with full-length anchored $\mathrm{E}$ or truncated secretory E protein, while both plasmids induced JEV neutralizing antibodies in mice. To achieve this, efforts are underway to further enhance the immunogenicity of JE DNA candidate vaccine.

Another alternative approach for controlling Japanese encephalitis is the reduction in mosquito vector population. It has been shown that the JEV can cause a long-lasting viremic phase in amplifying hosts. The virus can cause infection in pigs with the viremic phase last for 28 days, whereas the viremic phase in infected birds last for 4-5 days with a very high virus titer, about $10^{5} \mathrm{pfu} / \mathrm{ml}$ in a house sparrow. These long lasting viremia in amplifying hosts provide ample opportunities for the susceptible mosquito vectors to become infected after feeding on them. Therefore, if we can reduce the population of mosquito vectors, the chances are possible to control the epidemic of JEV in the endemic areas. The slow-release formulations of products made from microbial insecticides, i.e., Bacillus sphaericus, and Bacillus thuringiensis var. israelensis, have been used in field trials against certain species of mosquito larvae especially Culex quiquefasciatus, with a satisfactory result. However, it is very difficult to apply the aforementioned formulations of microbial insecticides' products in the breeding places of the mosquito vectors, because the mosquito larvae of Culex species are filter feeder, which feed on the surface of the water. All larvae of the mosquito vector species are found in polluted water. It has been shown that the effectiveness of microbial insecticides' products is not reached a satisfactory result. Efforts on the development of microbial insecticides for biological control of mosquito vector are underway in parallel with the recent advances in biotechnology 


\section{Natural cycle of Japanese encephalitis virus}

Japanese encephalitis virus (JEV) has long been recognized as a member of viruses, which has been classified in the genus Flavivirus of the family Flaviviridae. The natural transmission cycles involving avian or swine reservoir hosts, where culicine mosquitoes serve as vectors. The virus has ability to cause fatal infections in horses, and is transmitted to human by several species of culicine mosquitoes including Culex tritaeniorhynchus, Culex gelidus, and Culex vishnui in Thailand. In general, the natural cycle occurs as a zoonotic cycle of which either pigs or birds serve as vertebrate amplifying host and man appears to be accidental hosts. In addition to human disease, JEV produces abortion and neonatal death in pigs and death in horses, which are economically important in the area where Japanese encephalitis occurs.

In general, a three-way relationship between virus, host and environment that has evolved over millions of years, is considered as a basic requirement of a given mosquito-borne viruses to occupy a particular ecological niche. A certain virus is confined perhaps to the forests of one continent; it infects one or a small number of species of mosquitoes that habitually feed off one or a few species of vertebrate. Any given species of vertebrate that serves as an efficient host, it must be abundant, must reproduce rapidly, and above all musts maintain a high level of viremia for an adequate period. In its turn, any species of mosquitoes that will serve as an efficient vector, must have a sufficiently low threshold of infection by that virus, must then carry and shed the virus in its salivary secretions for life, but not be adversely affected by it, and must have a distribution, flight range longevity, and biting habits well adapted to the habits and habitats of its principal vertebrate host. Hence the virus flourishes indefinitely in a state of peaceful coexistence with vertebrate and mosquito host in which no one-get hurt. The troubles arise when the virus moves beyond this enzootic cycle.

\subsection{Virus properties}

It is quite interesting to learn how JEV replicates itself and continually circulates in nature. Japanese encephalitis virus, a 40 - to 50 -nm-sized enveloped virus, has a single positivestrand RNA genome. The RNA genome contains three structural (capsid, pre-M, and envelope) and seven nonstructural (NS1, NS2A, NS2B, NS3, NS4A, NS4B, and NS5) proteins (Chambers et al., 1999). An inactive vaccine is available against JEV, but multiple doses are required to confer protective immunity and some pathogenic side effects have been reported (Ku et al., 1994). There are no specific effective drugs available to treat Japanese encephalitis virus infections.

Four basic criteria in incriminating the mosquitoes as a vector of JEV have been met by Culex tritaeniorhynchus which including, i.e., isolation of JEV from naturally infected mosquitoes, laboratory demonstration of the ability of the mosquitoes to become infected by feeding on a viremic host, laboratory demonstration of the ability of these infected mosquitoes to transmit the virus during blood feeding, and evidence of blood feeding contact between the suspected mosquito vector and suspected vertebrate hosts under natural conditions. All evidences supported these criteria were demonstrated in Thailand (Grossman et al., 1974).

\subsection{Virus changes}

There are some evidences that the virus itself changes in nature during its replication cycles. In Flavivirus transmission, the salivary glands play a major role in establishing the vector 
status by their ability to produce and maintain a high titer of virus throughout the life of the vector. The replication of virus does not cause a cytopathic change in the salivary glands (Takahashi \& Suzuki, 1979). This event is very important for the virus itself to survive in nature. In addition to the ability of JEV that can replicate in various kinds of hosts and vectors, JEV also obtains its envelope from the modification of host cell membrane during the budding process. Thus, it has been postulated that genetic variation of JEV in nature may occur following several replication cycle in different kind of vectors and hosts. This hypothesis has been verified by the comparison of short nucleotide sequences of JEV isolates from various countries, and demonstrated that the similarity of the JEV isolates can be segregated into three groups, i.e., group I in which they were recovered from northern Thailand and Cambodia, group II were those isolates that recovered from southern Thailand, Malaysia, Sarawak and Indonesia, and group III were those isolates that recovered from Japan, China, Taiwan, the Philippines, Sri Lanka, India and Nepal (Chen et al., 1990). This finding provides insight into the evolution, transmission and possibly, pathogenesis of JEV. The possibility of virus changes still exists. Once the virus has been changed, it can lead to new epidemic in an appropriate ecological niche because it can escape from herd immunity, which developed against the previous form of the virus.

Mosquito-borne disease usually occurs when unnatural hosts become involved. When man lives in regions in which a particular mosquito-borne virus is enzootic he is vulnerable to infection and a few of those infected may suffer severe, even lethal, disease. Visitors such as tourists, soldiers, or forest workers are even more vulnerable as, unlike the indigenous population, they will not have acquired immunity from subclinical infection in childhood. In tropical countries where the mosquito vector is plentiful year round, the risk is always present and human disease is endemic. In regions subject to monsoonal rains, epidemics of mosquito-borne diseases may occur toward the end of the wet season due to the abundance of mosquito population. In some temperate countries, and particularly in arid areas, human epidemics of mosquito-borne disease occur following periods of exceptionally heavy rain. A different species of mosquito, with anthropophilic habits, may become involved in transmission of the virus to humans, and may then maintain the virus in a man-mosquitoman cycle without the intervention of the natural vertebrate or invertebrate host.

\subsection{Infections and pathogenesis}

The infection in man is usually initiated by the viruses are introduced through the skin by the bite of a mosquito vector. The virus is replicated in cytoplasm and maturation with budding process and the mature virions are released into cytoplasmic vesicles. The mature virions gain the envelope by modified the cell membrane of the host with the insertion of specific glycoprotein into the membrane. The mature virions inside cytoplasmic vesicles are easily released from the infected cells. Virions that enter the lymphatic capillaries are carried to the local lymph nodes, which act as filters. As they enter, virions are exposed to the macrophages lining the marginal sinus and are usually engulfed. They may be inactivated and digested and their antigens presented to the underlining lymphoid cells in such a way that the immune response is initiated. However, JEV can multiply in the macrophages which some virions may pass straight through the lymph node and eventually enter the blood stream. Since the macrophage and lymphocytes in the lymph node are constantly circulating in the lymph and blood vascular systems, virus may be passively transported around the body in these cells. The important target organ for JEV is CNS (White \& Fenner, 1984). 
The degree of severity of the disease in man caused by this virus is rather depended on the degree of neuronal destruction. Case fatality rates average about $10-20 \%$ and survivors are often with permanent neurological sequelae such as mental retardation, epilepsy, paralysis, deafness, and blindness (White \& Fenner, 1984).

The first know outbreak of JEV in Thailand occurred in 1964 in Phitsanulok Province of northern part of the country. Another outbreak was reported in 1969 in Chiang Mai Province with more than 650 cases and mortality rate of $27 \%$. Sporadic outbreak occurred in the following year in the same area and spread to adjacent provinces (Sangkawibha et al., 1982). It is of interest that the year 1964 was also a year in which very large JE epidemics occurred in Japan and Korea (Kono \& Kim, 1969). Hospital records in Chiang Mai Province reveal that periodic rainy season outbreaks of febrile encephalitis, probably caused by JEV, have occurred in northern Thailand since at least 1962 (Grossman et al., 1973).

Human JEV infections, however, are infrequent events. Incidence rates of clinical JEV infections in Thailand with recurrent JE epidemics have usually been between one and 10, and rarely higher than 30 per 100,000 population per year (Wang, 1964; Chen et al., 1990). The inapparent JEV infections occur more frequently, but, in the relatively sparse data available, infection rates of only about five per cent have been found in the few groups of people (mostly schoolchildren) who have been followed serologically through an epidemic season (Southam, 1956; Scherer et al., 1959a; Wang, 1964).

\subsection{Vector capability and transmission of virus}

The role of vector in maintaining viruses in nature is very critical and important for the virus. The most extensive epidemiologic studies of JEV have been carried out in northern temperate areas, where mosquitoes are not active in the winter. The virus reappears in the same locality year after year, and consequently considerable effort has been devoted to determining how the virus survives when its vectors are inactive. In fact, JEV had been recovered from adult mosquitoes reared from field-collected larvae and never exposed to JEV in the laboratory (Mitamura et al., 1939). This finding and the reports of transovarial transmission by mosquitoes of La Crosse virus (Watts et al., 1973), and other viruses have led to the experimental studies of transovarial transmission of JEV by mosquitoes. It was shown that such transmission could be demonstrated by Aedes albopictus and Aedes togoi in 1978 (Rosen et al., 1978). Thus, transovarial transmission may serve as one of alternative ways for JEV survives the winter in the northern temperate zone. But transovarial transmission may not be necessary for JEV in tropical areas where mosquito vectors and amplifying hosts are abundant all year round.

For vector roles of JEV, it has been shown that a small number of closely related species of Culex mosquitoes serve as vectors. It is very interesting to note that some species of mosquitoes are not only serving as vectors for the virus transmission, they may also serve as an important tool in epidemiological studies. It is important to appreciate the difficulties involved in this sort of epidemiological detective work. Mosquito-borne viruses are generally so difficult to isolate from man, thus field-collected mosquitoes are the important specimens for virus isolation attempts and in fact most of them are originally discovered in mosquitoes collected from tropical forests or from "sentinel" animals left overnight in mosquito-infested areas. However, only certain species of Culex mosquitoes can serve as vectors for JE virus. Several factors may play an important role for species-specific activity in virus transmission. It is believed that gut barrier for virus replication is one factor. 


\subsection{The relationships between virus and mosquito}

The capacity of a vector to transmit high titers of virus is an important factor in the vector potential of the species in addition to the susceptibility of the vector to the virus. In this sense, concentration of JEV as high as $10^{4.2}$ in the saliva of Culex tritaeniorhynchus for prolonged incubation periods demonstrate the high vector potential of this mosquito (Takahashi, 1976). It has been shown that when mosquitoes are maintained under autumn or winter conditions virus concentrations of whole mosquitoes are lower than in those exposed to summer conditions, and the virus antigen is restricted to the midgut (Kay et al., 1989).

Culex tritaeniorhynchus is known as the principal vector of JEV in many countries, i.e., Japan (Buescher et al., 1959), Okinawa (Hurlburt \& Nibley, 1964), and Thailand (Simasathien et al., 1972). A complete study on vectors of JEV in Thailand was done in Chiang Mai Valley. It was shown that peaks in the population densities of Culex fuscocephala, Culex gelidus and Culex tritaeniorhynchus, as measured by weekly light-trap collections, occurred during the rainy season (April-October) at the time of human and animal JEV infections. Analysis of mosquito blood meals indicated that, while the three vector species fed on humans and a variety of domestic animals, their most frequent hosts were buffalo and cattle. Feeding activity by the three vector species began after dark and was maintained throughout the night. These mosquitoes were predominantly exophilic, and very few were collected inside houses. All these findings suggest that the three incriminated vector species act principally to maintain a cycle of JEV infection in domestic animal populations that only occasionally involves humans in the Chiang Mai Valley (Gould et al., 1974).

\subsection{Man as carrier}

Man when bitten by an infected mosquitoes, develops a viremia about the end of the incubation period (usually about 5 to 6 days), be remains infective for other Culex mosquitoes biting him during the first 4 or 5 days of illness. The new mosquito after ingesting virus can transmit beginning 8 to 10 or more days later and for as long as it lives. From this we may assume that a person infected with a JEV in Bangkok may fly to Songkhla or other cities or neighboring countries before he is ill, then become ill there and be a source of virus for the local Culex mosquitoes, which 10 days later pass it on locally and soon a new epidemic center occurs. From here it is carried up river by boat, or elsewhere by train, car or oxcart to other smaller cities and towns. However, the trouble with all of these assumptions applied of Japanese encephalitides spread is that JEV is known to be present endemically in all of these places for a long time, being carried about originally in this same way before these epidemics of JE started. Something new must have intervened. However, once it is introduced as viremia in a returning traveler, animal or bird, including migrants, for example, or in an infected insect vector accidentally imported by airplane, ship or car, they probably would not become established successfully in the country. Eventually, after the virus is landed in a suitable habitat, they could become established and might even become endemic.

\subsection{Vertebrate hosts}

Another important factor in natural cycle of JEV is vertebrate host. Japanese encephalitis viruses are believed to be maintained in populations of certain vertebrates, being transmitted among them by mosquitoes and other hematophagous arthropods, with man becoming tangentially infected when entering the environment in which these viruses are circulating. 
The presence of antibodies in significant numbers of a particular species of bird or animal suggests that it may be an important natural reservoir or amplifier host (Buescher et al., 1959b). An investigation in Chiang Mai Valley showed that each rainy season enormous numbers of the vector mosquitoes emerged from the flooded rice fields and irrigation ditches of the valley to feed on the numerous buffalo, cattle and pigs present in the rural areas. An analysis of the data suggested that pigs play a major role in the transmission of JEV in the Chiang Mai Valley (Grossman et al., 1974). Other studies also confirm that pigs are important hosts for amplification of virus dissemination in the epidemic region (Buscher \& Scherer, 1959) and for maintenance of virus cycling in the endemic region (Simpson et al., 1970).

It was also reported in other studies that many vertebrates were infected (SEATO Med Res Lab, 1969). One experimental infection study demonstrated that adults of a mammal, Menetes berdmorei, were susceptible to infection with JEV. Also, one species of rat, Rattus exulans, might be infected on occasion (William \& Imlarp, 1972).

Birds are considered as important hosts for JEV because Culex mosquitoes are readily fed on birds. It was demonstrated that 20 to 37 per cent of wild Japanese tree sparrows had neutralizing antibodies to JEV. Sparrows free of antibodies were inoculated with 10,000 plaque-forming units of JEV. None of the birds became clinically ill. Virus could be detected in blood plasma during the first three days after inoculation but not thereafter (Yuill, 1969). It has been postulated that a certain species of bird (night heron) as well as migrant bird species might serve as a good vehicle to carry virus from one place to other place in a very long distance during the period of acute viremia (Scherer et al., 1959b). However, migrations of most bird species do not cover great distances such as from tropical to temperate areas in the few days that high titer primary viremia would persist. One may hypothesize transmission of infection to susceptible migrants at intermediate resting areas while in transit. Thus, birds moving in great distance may possibly serve as a source of vector infection.

\subsection{Reptile}

Beside mammals, it is quite interesting to note that two common species of house gecko lizards, Hemidactylus frenatus and Platyurus platyurus, are susceptible to JEV infection. It was shown that they developed viremia for six days with the concentration of virus in the blood high enough to be picked up by mosquitoes, Aedes aegypti (in the amount of 0.006- $0.06 \mathrm{ml}$ ) in which JEV could be detected by suckling mice inoculation and LLC-MK 2 cell culture inoculation (Yuill et al., 1968; Yuill, 1969). It turns out that mosquitoes can be used as successful as needles and syringes for drawing blood from house gecko lizards for viremia determination, despite the fact that the mosquitoes usually draw less blood $(0.006-0.06 \mathrm{ml})$ from each gecko than that is obtained with needle and syringe ( 0.05 to $0.1 \mathrm{ml})$. This finding is very useful in studying ecology of mosquito-borne viruses. Thus, the virological studies with JEV can be done, at daily intervals for one week when small size house gecko lizards are used as hosts for virus infection. Drawing blood from these very small ( $3-10 \mathrm{~g})$ lizards with a syringe and 27-gauge needle invariably proved fatal.

It has been demonstrated clearly by Grossman and his coworkers (Grossman et al., 1974) that a simple pattern of endemic in Thailand, year-round transmission of JEV between Culex mosquitoes and pigs seems sufficient to account for persistence of JEV in Chiang Mai Valley, and the appearance of human encephalitis cases. It was found that the human epidemics which occurred each May through August in the Valley were probably a reflection of a 
logarithmic increase in vector mosquito populations in April and early May. It coincided with the onset of the seasonal rains and was followed closely by larger numbers of infected mosquitoes as reflected by increased JEV transmission rates in sentinel pigs (Grossman et al., 1974). Human epidemics probably resulted from greater exposure to these infected mosquitoes. The apparent resistance of bovines to infection (Johnsen et al., 1974) the slow rate of turnover in the bovine population, and bovine attractiveness to vector mosquitoes (Gould et al., 1974) indicate that bovines may actually suppress JEV infections, as has been suggested in India (Carey et al., 1969).

Questions have been raised concerning low number of JEV cases during high number of vector population in certain endemic areas. Several factors are used to explain these facts, i.e., blood feeding on non-amplifier species of vertebrates, blood feeding on the immune portion of amplifier populations, inefficient transfer from infected mosquito to susceptible amplifier animal to susceptible mosquito. Not all susceptible amplifier hosts fed upon by infected Culex tritaeniorhynchus develop high enough viremia to infect other feeding mosquitoes, and high vector mortality between infectious blood meal and the second postinfection oviposition.

\subsection{Ecology of mosquito vector}

Concerning the ecology of mosquito vector, some factors of greatest relevance to the abundance of JE vectors include the development of irrigation agriculture, e.g., utilization of rice fields and irrigation waste water by Culex tritaeniorhynchus, inadequate disposal of polluted water resulting from burgeoning urbanization and industrialization, e.g. Culex quinquefasciatus.

In most areas in which JE in endemic Culex mosquitoes are now far more important than Aedes species in the transmission of the virus to humans, but species of the latter genus may be significant in the basic ecological cycle of JEV such as vectors to humans in some types of relatively undisturbed natural habitat. For example, although Culex tritaeniorhynchus and domestic pigs are now the most important hosts of JEV in Japan from the point of view of human infection, swine have been reared in significant numbers in Japan only since the opening of that country to contact with the outside world in 1853. The southeastern Soviet Union is the one area where the epidemiology of JEV has been studied in a setting not greatly changed by humans. Russian investigators consider three of Aedes (togoi, japonicus, and koreicus) as important vectors of JEV to humans in some types of habitat in this region (Petrischeva et al., 1963).

A small number of closely related species of Culex mosquitoes serve as vectors, and many vertebrates are infected. Pigs in particular, are important hosts for amplification of virus dissemination in the epidemic region (Buescher and Scherer, 1959) and for maintenance of virus cycling in the endemic region (Simpson et al., 1970). Although the vectors are much more attracted to pigs than to man, it is presumed that the appearance of viremic pigs each spring in the temperate zone allows a large number of mosquitoes to become infected resulting in virus transmission to humans and encephalitis epidemic.

\section{Prevention and control}

Because of the shortage of appropriate form of specific treatment for Japanese encephalitis, control of the disease relies mainly on the control of the mosquito vector, on the early 
identification of cases, and if possible, the isolation of cases from contact with vector mosquitoes. Vaccine against JEV is also available for high-risk group of people such as children in endemic area, military men, physicians and nurses. In addition, vaccine against JEV for pig vaccination is also available which is very useful in terms of reducing the number of susceptible amplifying hosts.

There are three JEV vaccines that currently available for prevention of JEV. They are inactivated vaccine derived from mouse brains; cell culture-derived inactivated vaccine, and cell culture-derived live attenuated vaccines . Formalin-inactivated vaccine (JE-Vax) is the only vaccine currently in used internationally. It is produced from mouse brain tissue and is manufactured by the Research Foundation for Microbial Disease (BIKEN), Osaka, Japan, and also by the Government of Pharmaceutical Organization (GPO), Bangkok, Thailand. The GPO obtains the technical assistance from BIKEN and Japanese government to establish local production of inactivated mouse brain-derived vaccine from Nakayama and Beijing strains of JEV. The GPO has the capacity to produce only $40 \%$ of the national vaccine need. All of the rest are imported vaccine. Although it is effective, multiple-dose regimen is needed with the relatively high cost and problems with reactogenicity complicated its use. Inactivated and live-attenuated JE vaccine, prepared from JEV strain SA14-14-2 grown in primary hamster kidney (PHK) cells culture, have been developed and used only in China. Sporadic cases of viral encephalitis in Thailand have been noted in the northern part before 1969. An epidemic transmission of JE was first recognized in 1969 when an outbreak leading to 685 cases occurred in the Chiang Mai valley. Yearly outbreaks numbering in the thousands of cases and hundreds of deaths recurred in the northern region and JE became a leading cause of mortality and disability in children. Hyperendemic JE transmission has subsequently spread within Thailand, and the adjacent area in Burma (Tsai, 2000). According to the continue public health impact of JE in Thailand, it has led to effort in childhood immunization and vaccine production in 1985.

It was demonstrated by hemagglutination inhibition and neutralization assay that there are definitive antigenic differences among JEV Thai strain and between Thai strains and the standard subtypes, Nakayama and Beijing strains (Ali et al., 1995; Ali \& Igarashi, 1997). Most of JEV isolated in Thailand are belonging to genotype I, while some belonging to genotype II, which strains Nakayama and Beijing are belonging to genotype III (Ali \& Igarashi, 1997). The monovalent vaccine derived from JEV strain Nakayama or bivalent vaccine consisting of Nakayama and Beijing-1 strains provide $91 \%$ protective efficiency in either protocol in Thai children. These currently available vaccines are able to induce high levels of protective immunity against JEV belonging to heterologous genotypes. However, it is possible that vaccines produced from JEV strains isolated in Thailand may induce higher level of protective immunity against the locally circulating strains (Kurane \& Takasaki, 2000).

\subsection{Vaccine development}

The development of a vaccine that would induce rapid protection in people and animals is currently remained as an important issue. New generation of safe chimeric viruses that are unable to infect mosquitoes is currently ongoing in the development and preclinical studies. This would be a major step toward production of live-attenuated vaccine that is safer for the environment and would minimize the risk for vaccine-born outbreaks as reported in 1970s for TC-83 vaccine. It has been proposed that live-attenuated JEV vaccine has several 
advantages including small dose is required for vaccination, a secretory IgA is produced against certain virus agent and the immune response last longer in recipients. This type of vaccine is an attractive one in vaccine development against several virus agents. An attenuation of virulence of the viruses is one of selected markers used for the development of live-attenuated vaccines.

There is one live-attenuated JE vaccine currently available and being used in China. Liveattenuated JE vaccine derived from SA14-14-2 strain has shown several advantages comparing to inactivated vaccine including lower dose in vaccination, low cost in vaccine production, and induction of long-lasting immune response in immunized children. This attenuated virus has small plaque phenotype. The potential of small plaque size mutants to be used as live-attenuated vaccine strains has been intensively investigated by several investigators. It has been shown that temperature sensitive (ts) mutants of dengue type 4 virus and dengue 2 virus which have small plaque phenotype appeared to be attenuated in mice that may be useful for the development of a recombinant live attenuated vaccine of dengue virus (Blaney et al., 2002, Hanley et al., 2002, Huang et al., 2003). The small plaque mutants of other flaviviruses including West Nile virus (WNV) and tick-borne encephalitis virus (TBE), Murray Valley encephalitis virus (MVE), and JEV that are increase in cells infectivity and increase in affinity of glycosaminoglycan binding, have shown their virulence were attenuated in mouse model (Lee et al., 2004, Lee \& Lobigs, 2002, Mandl et al., 2001). In addition, almost all strains of JEV, which are small plaque size variants on BHK-21 cells, except for JaGAr 01, are found to be correlated with the virulence attenuation of the viruses in mice (Kimura et al., 1973). Thus, it is quite interesting to find a small plaque size variant as a short cut to be used for the development of the vaccine.

Live attenuated JE vaccine derived from SA14-14-2 strain has shown several advantages comparing to inactivated vaccine including lower dose in vaccination, low cost in vaccine production, and induction of long-lasting immune response in immunized children. This attenuated virus has small plaque phenotype. The potential of small plaque size mutants to be used as live-attenuated vaccine strains has been intensively investigated by several investigators. It has been shown that temperature sensitive (ts) mutants of dengue type 4 virus and dengue 2 virus which have small plaque phenotype appeared to be attenuated in mice that may be useful for the development of a recombinant live attenuated vaccine of dengue virus (Blaney et al., 2002, Hanley et al., 2002, Huang et al., 2003). The small plaque mutants of other flaviviruses including West Nile virus (WNV) and tick-borne encephalitis virus (TBE), Murray Valley encephalitis virus (MVE), and JEV that are increase in cells infectivity and increase in affinity of glycosaminoglycan binding, have shown their virulence were attenuated in mouse model (Lee et al., 2004, Lee \& Lobigs, 2002, Mandl et al., 2001). In addition, almost all strains of JEV, which are small plaque size variants on BHK-21 cells, except for JaGAr 01, are found to be correlated with the virulence attenuation of the viruses in mice (Kimura et al., 1973). Thus, it is quite interesting to find a small plaque size variant to use for the development of the vaccine.

It has been shown that there is a good correlation between small plaque size and attenuation of viruses including several members of flavivirus, i.e., Dengue virus type 2, West Nile virus, Tick-borne encephalitis virus, and Murray Valley encephalitis virus (Tsai, 2000; Blaney et al., 2002; Hanley et al., 2002; Lee et al., 2004; Lee \& Lobigs, 2002; Mandl et al., 2001; Huang et al., 2003). The vaccine strain, SA 14-14-2 of JEV, also has a small plaque size and grows quite well in PHK cells. This strain is currently used to produce live attenuated 
vaccine in China (Tsai, 2000). It has been described that small plaque size phenotype is influenced by the burst size and short incubation. In addition, the sensitivity to interferon and growth conditions of viruses such as the nature of medium and temperature of incubation of infected cells may be involved in the production of small plaque size of the virus. It was documented that the small plaque variants of Sindbis virus were more susceptible to the action of interferon than a large plaque variant (Kimura et al., 1973).

Serial passage the wild type virus in cell culture is a classical method for the selection of the attenuated strain of viruses. Small plaque size phenotype of the virus comparing to their parent strain are used as a marker for the selection of the virulence attenuation. Moreover, amino acid replacement in $\mathrm{E}$ protein is one of the markers to determine the phenotypic changes in neuro-virulence of the viruses as shown by several investigators. The most important is that the difference of amino acid changes in E protein of JEV may unique for each strain. However, these markers are useful to determine virulence attenuation for development of live-attenuated vaccine. To further understand the exact molecular mechanism of the small plaque mutants, the complete nucleotide sequence need to be done.

Attempts have been made to select small plaque variants from the local strain of JEV in Thailand. It was demonstrated that the two suspected temperature-sensitive mutants of Japanese encephalitis virus strain KE-093 had an amino acid substitution, lysine for glutamic acid, in envelope protein at residue E-83 in the small plaque variants. The growth patterns and neurovirulence of these two small plaque variants of Japanese encephalitis virus in suckling mice remained the same as that of the parent strain, which suggested that small plaque phenotypes was not always associated with attenuation in vivo (Lorroengsil et al., 2008). In contrast, it has been shown that JEV strain SA 14-14-2, the vaccine strain, could replicate in C6/36 cells better than the parent strain (Bhatt et al., 2000). TBE virus mutant (Oshima C1-1) that was selected by subculturing the parent strain (Oshima 5-10) in BHK-21 cells was replicated better than the parent virus. The TBE virus mutant was attenuated for neuro-invasiveness in mouse model (Goto et al., 2003). This advantage is useful for the production of the live-attenuated vaccine using cell culture techniques. However, one precaution should be aware of is that the possibility of the vaccine strain that are replicating in the body of vaccinated people may serve as a source for the mosquito vector to feed on, and may revert back to the virulent form of the virus again.

\subsection{DNA vaccine}

The progresses in the development of DNA vaccine in Thailand are in the early phase of the development. Our group is also trying to use the most recent pathogenesis data to design a therapeutic vaccine that would reverse already established encephalitis and help clear the virus from the brain.

Plasmid DNA-based vaccination strategies have become an active area of research over the past decade due to their potential to produce safer and cheaper vaccines. These vaccines could be delivered to recipients by intra-muscular (IM) injection or intra-dermal (ID) administration using a gene gun. IM inoculation of plasmid DNA vaccines to mice induces predominantly $\mathrm{T}$ helper 1 (Th1) immune responses, while T helper 2 (Th2) type immune responses are generated following the ID delivery. The isotypes of antibodies and the types of cytokines induced by the two methods differ and this could have bearing on the efficacy of the vaccine candidate. 
Attempts have been made to construct the plasmid DNA vaccine against JEV by trying to include JEV $e$ gene in the plasmid DNA. It has been shown that these plasmids are capable of synthesizing JEV premembrane (prM) and E proteins, which have been evaluated in mice. Both forms of $\mathrm{E}$ protein however generated JEV neutralizing antibodies that provided significant protection to mice against lethal JEV challenge.

The envelope (E) protein of JEV is also the interesting target for vaccine development. Since the E glycoprotein contains antigenic determinants for hemagglutination and neutralization. Mutations in the $E$ gene are often responsible for significant alterations in the biological functions of the virus and may affect virulence (Richman et al., 2002). It has been reported that there are the constructed recombinant DNA encoding full-length and sub-fragment E protein (Chen et al., 1999; Kaur \& Sachdeva, 2002; Ashok \& Rangarajan, 2002), C-terminal part and soluble form of E protein (Chia et al., 2001). These protein products induce neutralizing antibody and protective immunity in mice.

E protein is known as an important protein, which plays roles in virion assembly, receptor binding, membrane fusion, and is a major target for neutralizing antibodies (Chambers et al., 1990). It has been noted that mutations in the $\mathrm{E}$ protein are often responsible for significant alterations in the biology of the virus and may affect virulence (Tiroumourougane et al., 2002; Richman et al., 2002; Burke \& Monath, 2002; Chambers et al., 1990; Heinz, 2003). Phenotype changes among flaviviruses have also been found to associate with amino acid alteration of $\mathrm{E}$ protein. It has been shown that seven amino acids in the virulent parent SA 14 have been substituted in attenuated vaccine clones, SA 14-14-2/PHK and SA 14-14-2/ PDK, when their genomes are compared. Four of them are located in E protein including E-138, E-176, E-315, and E-439. Three amino acids are located in nonstructural protein including NS2B-63, NS3-105, and NS4B-106. Several amino acids are also mutated, i.e., glutamic acid to lysine at E-138, isoleucine to valine at E-176, alanine to valine at E-315, lysine to arginine at E-439, glutamic acid to aspartic acid at NS2B-63, alanine to glycine at NS3-105, and isoleucine to valine at NS4B-106 (Ni et al., 1995). The attenuation concerning neuro-invasiveness in mice of the prototype JEV strains, Nakayama-O and an Indian 826309, was observed following six passages in Hela cells. Nine and eight amino acids substitutions were found in $\mathrm{M}$ and $\mathrm{E}$ protein of the attenuated Nakayama-O and an Indian 826309, respectively. The common one of amino acid substitution of these two attenuated viruses was alanine to valine at E-366 (Cao et al., 1995). It has been proposed that the mutation of the flavivirus strains that have been attenuated by serial passage do not share common genetic mutations that are associated with their phenotypes. However, there is a notable exception that the identical mutation from glutamic acid to lysine occurred at amino acid residue E-138 of the IC47 infectious clone-derived variants from JEV strain JaOArS982 and of the vaccine strain SA 14-14-2 (Kinney and Huang, 2001).

E protein has been noted as the most important antigen in providing of protective immunity against JEV. Among three domains of E protein, neutralizing epitopes of domain III has been described. They were including of residues 308, 310, and 311 of louping ill virus; 384 and 386 of TBE virus; 305 of yellow fever virus; 307, 383-389, and 333-351 of dengue viruses; $306,331,333,373-399$, and 387 of JEV (Lin \& Wu, 2003). Immunization with 27 amino acid of JEV E protein which is present on Johnson Grass Mosaic virus-like particles able to induce neutralizing antibodies without using adjuvant and protect mice from lethal challenge (Manishia \& Vrati, 2003). This peptide, peptide A, contained residues 373 to 399 of JEV E protein was chosen for this study. Moreover, it has been shown by using complementary 
structural modeling and site-directed mutagenesis of domain III of E protein of JEV in E. coli with monoclonal antibody (Mab) E3.3 that serine 331 and aspartic acid 332 have a potential to be neutralizing epitopes ( $\mathrm{Lin} \& \mathrm{Wu}, 2003$ ). Another peptide, peptide B, contained residues 325 to 333 was also selected.

It has been shown that mouse immunized with virus-like particles (VLPs) presenting amino acid 373 to 399 from JEV E protein on domain III generated JEV neutralizing antibody without using adjuvant, and these mice were protected against a lethal JEV challenge (Manishia \& Virati, 2003). It was demonstrated by site-directed mutagenesis that the functional domain at Ser331 and Asp332 on domain III of JEV E protein interacted with neutralizing monoclonal antibody (Mab) E3.3 (Lin \& Wu, 2003).

One of interest is the determination of the antigenic determinant of JEV from sub-fragment in domain III region of $e$ gene. There is a possibility to insert two selected peptides that have been chopped into small overlapping peptides, synthesized, and linked with hepatitis B core peptide (HBc Ag), which is a B-cell epitope and recognized by mouse MHC. This $\mathrm{HBC} A g$ may help JEV peptides in an activation of antibody response in immunized mice. The peptides, which show neutralizing activity against JEV, may serve as the antigenic epitopes of the virus. This antigenic epitopes will be useful in second-generation vaccine development against the local JEV in the future.

It has been shown that serial passage of virus resulted in cell-adapted mutant that is attenuated in virulence in mice. Some of these mutants have changed in net positive charge of their proteins. They have high affinity for glycosaminoglycans (GAGs), which are highly-sulfate polysaccharides that are present almost ubiquitously on cell surfaces (Goto et al., 2003; Mandl et al., 2001). JEV replication in mice might require other viral or host cell-specific factors which do not present in BHK-21 cells infection. However, the mechanism by which cell-adapted flaviviruses undergo attenuation in vivo is not well understood.

Protection against JEV is mainly antibody dependent. Virus neutralizing antibody alone is sufficient to impart protection. Previous report has been documented that formalininactivated JEV vaccine does not induces CTLs but provides protection to vaccinees against JEV (Pan et al., 2001). Therefore, B cell epitopes on JEV E protein are important determinants of protection against virus infection. The whole E protein was not necessary for activating immune response but the small fragments of $\mathrm{E}$ protein were sufficient for eliciting the immune response and protect against JEV challenge (Lin \& Wu, 2003; Kaur \& Sachdeva, 2002; Chia et al., 2001).

As mentioned by previous reports that the whole protein was not necessary for activating immune responses, small protein fragments that contain antigenic epitopes are sufficient for eliciting the desired immune response. Peptide fragments of several pathogens, such as Brucella abortus, Trichinella spiralis and Plasmodium yoelii have potential to be used as vaccines (Moynihan \& Howard, 2001). Peptide vaccines are easy to produce, biological stable at high temperature, no infectious agent present in the preparation and safe for human use. A major problem of peptide vaccine is their poor immunogenicity. Synthetic peptide need to be presented with the strong adjuvant or large carrier proteins to elicit good immune responses (Manishia \& Virati, 2003). An envelope E gene of Japanese encephalitis virus genotype I, Thai strain KE-093 was successful cloning and heterologous expression in Escherichia coli Rosetta 2 strain (Witthajitsomboon et al., 2010). Attempts to develop DNA vaccine are going on by using the cloned $e$ gene. 
The rodent models have been used to evaluate vaccine candidates in pre-clinical studies, and nonhuman primates are usually the models of choice as they provide a robust system for evaluation of vaccine candidates. The Old World monkeys have predominantly been used in these types of studies with rhesus (Macaca mulatta) and cynomolgus (Macaca fascicularis) monkeys being most popularly used for evaluation of vaccine candidates against various infectious diseases, including those caused by Flaviviruses. It has been shown that the immunogenicity of premembrane-envelop proteins ( $\mathrm{pMEa}$ and pMEs) delivered intramuscularly (IM) or intradermally (ID) in rhesus monkeys resulted in the DNA immunization induced protective levels of JEV neutralizing antibodies and generated robust memory that led to a rapid and sustained anamnestic response in monkeys sham challenged with mouse brain-grown, formaldehyde inactivated commercial vaccine. Several JEV proteins were evaluated in the DNA vaccine modality for their ability to induce protective immunity in the murine system. These include plasmids could express non-structural protein 1 (NS1), E or prM and E proteins of JEV. It was shown that variable degree of efficacy in murine model systems with plasmids expressing prM and $\mathrm{E}$ proteins conferring high degree of protection of mice against lethal JEV challenge, largely due to their ability to induce JEV neutralizing antibodies. Two plasmids could express prM protein along with full-length anchored E or truncated secretory E protein, while both plasmids induced JEV neutralizing antibodies in mice. To achieve this, efforts are underway to further enhance the immunogenicity of JE DNA candidate vaccine.

\section{Vector control}

\subsection{Microbial insecticides}

An alternative approach for controlling Japanese encephalitis or any of mosquito-borne viruses is the reduction in mosquito vector population. It has been shown that the JEV can cause a long-lasting viremic phase in amplifying hosts. The virus can cause infection in pigs with the viremic phase last for 28 days, whereas the viremic phase in infected birds last for 4-5 days with a very high virus titer, about $10^{5} \mathrm{pfu} / \mathrm{ml}$ in a house sparrow(Yuill, 1969). These long lasting viremia in amplifying hosts provide ample opportunities for the susceptible mosquito vectors to become infected after feeding on them. Therefore, one way to block the transmission of the virus can be achieved by reducing the number of mosquitovector populations. This activity will lead to the reduction of new cases of infected patients in the endemic areas.

The world Health Organization (WHO) has recommended utilization of Bacillus thuringiensis var. israelensis (Bti) as an agent for biological control of mosquitoes since 1978 (Arata et al., 1978). The recommendation was based on the facts that Bti produces proteinaceous parasporal crystals during sporulation. These crystals are composed of multiple proteins ranging from 26 to 135 kilodaltons $(\mathrm{kDa})$ in size with act as a protoxin (135 $\mathrm{kDa}$ ). The crystals are lethal to larval mosquitoes (Goldberg \& Margalit, 1977), and to blackflies (Undeen \& Nagel, 1978). No effect is observed on non-target aquatic insects, fish, or frog larvae (Garcia \& Goldberg, 1978). It has been shown that several chemicals can persist for a long time in the environment, they are hazardous to humans. Thus, the development of biological controls as an alternative means of mosquito vector control is desired. 


\subsubsection{Bacillus thuringiensis var. israelensis}

One of the most successful insect pathogens used for insect control is the bacterium Bacillus thuringiensis subspecies israelensis, which presently is $\sim 2 \%$ of the total insecticidal market. $B t i$ is almost exclusively active against larval stages of different mosquito species, i.e., Aedes aegypti, Culex quinquefascatus, Culex gelidus, and Culex tritaeniorhynchus and kills the insect by disruption of the midgut tissue followed by septicemia caused probably not only by Bacillus thuringiensis but probably also by other bacterial species (Raymond et al., 2010). The action of Bacillus thuringiensis relies mainly on insecticidal toxins that are active during the pathogenic process. In addition, these bacteria also produce an array of virulence factors that contribute to insect killing (Bravo et al., 2005). Upon sporulation, Bacillus thuringiensis produces insecticidal crystal inclusions that are formed by a variety of insecticidal proteins called Cry or Cyt toxins. These toxins show a highly selective spectrum of activity killing a narrow range of insect species. The Cry and Cyt toxins belong to a class of bacterial toxins known as pore forming toxins (PFT) that are secreted as water-soluble proteins and subsequent undergo conformational changes in order to insert into the membrane of their hosts. Despite the limited use of Bacillus thuringiensis products as spray-able insecticides, Cry toxins have been introduced into transgenic crops providing a more targeted and effective way to control insect pests in agriculture. Concomitantly, this approach has resulted in significant reduction in the use of chemical insecticides in places where this technology has been embraced.

\subsubsection{Bacllus sphaericus}

One promising agent that may be used as microbial insecticides is a spore-forming bacillus, Bacillus sphaericus. This bacterium is an aerobic, gram-positive, spore-forming bacillus, which is also widespread in soil and aquatic environments. Some strains produce a toxin which is lethal when ingested by filter-feeding mosquito larvae. Kellen and his colleagues described the isolation of a larvicidal Bacillus sphaericus strain $\mathrm{K}$ from moribund larvae in the U.S. in 1965 (Kellen et al., 1965). A more pathogenic strain, strain SSII-1, was later isolated by Singer (Singer, 1973) from infected larvae collected in India. Subsequently, more highly toxic strains were isolated from around the world, among which are strain 1593 from Indonesia (Singer \& Murphy, 1976), strain 2297 from Sri Lanka (Wickremesinghe \& Mendis, 1980), and strain 2362 from Nigeria (Weiser, 1984). The potency and specificity of the Bacillus sphaericus toxins make them promising agents for biological control of mosquito pests.

Comparison of the larvicidal toxins from Bacillus sphaericus strains SSII-1, 1593 and 2362 revealed several important differences (Myers et al., 1979). Bacillus sphaericus yielded better results against larvae of Culex quinquefasciatus and Anopheles minimus than that of Aedes aegypti larvae (Pantuwatana, 1989).

Attempts have been made to produce several formulations of microbial insecticides, Bacillus sphaericus, and Bacillus thuringiensis var. israelensis (Bti). Microbial insecticides have been proposed as substitutes for chemicals because they have a narrow and specific spectrum of activities that enable them to kill only certain insect species. But their use is limited since most microbes show a narrow spectrum of activity that enables them to kill only certain insect species. Moreover, they have low environmental persistence and they require precise application practices, since many of these pathogens are specific to young insect larval stages or are sensitive to irradiation. 
The slow-release formulations of products made from microbial insecticides, i.e., Bacillus sphaericus, and Bacillus thuringiensis var. israelensis, have been used in field trials against certain species of mosquito larvae especially Culex quiquefasciatus, with a satisfactory result. However, it is very difficult to apply the aforementioned formulations of microbial insecticides' products in the breeding places of the mosquito vectors, because the mosquito larvae of Culex species are filter feeder, which feed on the surface of the water. All larvae of the mosquito vector species are found in polluted water. It has been shown that the effectiveness of microbial insecticides' products is not reached a satisfactory result. Efforts on the development of microbial insecticides for biological control of mosquito vector are underway in parallel with the recent advances in biotechnology.

\section{References}

Ali, A., Igarashi, A., Paneru, L. R., Hasebe, F., Morita, K., Takagi, M., Suwonkerd, W., and Tsuda, Y. 1995. Characterization of two Japanese encephalitis virus strains isolated in Thailand. Arch. Virol. 140: 1557-1575.

Ali, A., and Igarashi, A. 1997. Antigenic and genetic variations among Japanese encephalitis strains belonging to genotype I. Microbiol. Immunol. 41: 241-252.

Arata, A.A., Chapman, H.C., Cupello, J.M., Davidson, E.W., Laird, M., Margalit, J., and Roberts, D.W. 1978. Status of biocontrol in medical entomology. Nature (London) 276: 669.

Ashok, M.S., and Rangarajan, P.N. 2002. Protective efficacy of a plasmid DNA encoding Japanese encephalitis virus envelope protein fused to tissue plasminogen activator signal sequences studies in a murine intracerebral virus challenge model. Vaccine 20: 1563-1570.

Bhatt, T.R., Crabtree, M.B., Guirakhoo, F., Monath, T.P., and Miller, B.R. 2000. Growth characteristics of the Chimeric Japanese encephalitis virus vaccine candidate, ChemeriVax-JE (YF/JE SA14-14-2), in Culex tritaeniorhynchus, Aedes albopictus, and Aedes aegypti mosquitoes. Am. J. Trop. Med. Hyg. 62: 480-484.

Blaney, J.E., Johnson, D. H., Manipon, G.G., Firestone, C., Hanson, C.T., Murphy, B.R., and Whitehead, S.S. 2002. Genetic basis of attenuation of Dengue virus type 4 small plaque mutants with restricted replication in suckling mice and SCID mice transplanted with human liver cell. Virology 300: 125-139.

Bravo, A., Gill, S.S., and Soberón, M. 2005. Bacillus thuringiensis mechanisms and use. In: L.I. Gilbert, K. Iatrou and S.S. Gill, Editors, Comprehensive Molecular Insect Science, Elsevier BV (2005) ISBN 0-44-451516-X, pp. 175-206

Buescher, E.L., and Scherer, W.R. 1959. Ecologic studies of Japanese encephalitis virus in Japan. IX. Epidemiologic correlations and conclusions. Am. J. Trop. Med. Hyg. 8: 719722.

Buescher, E.L., Scherer, W.F., Rosenberg, M.Z., Gresser, I., Hardy, J.L., Bullock, H.R. 1959a. Ecologic studies of Japanese encephalitis virus in Japan. II. Mosquito infection. Am. J. Trop. Med. Hyg. 8: $651-654$.

Buescher, E., Scherer, W., Rosenberg, M., and McClure, H.E. 1959b. Immunologic studies of Japanese encephalitis virus in Japan. III. Infection and antibody responses of birds. J. Immunol. 83:605-613.

Burke, D.S., \& Monath, T.P. 2002. Flaviviruses. In: Knipe DM, Howley PM editors. Fields Virology vol.1, $4^{\text {th }}$ ed. ASM Press, Washington DC. 
Cao, J.X., Haolin, N., Wills, M.R., Campbell, G.A., Sil, C.B., Ryman, K.D., Kitchen, I., and Barrett, A.D.T. 1995. Passage of Japanese encephalitis virus in HeLa cells results in attenuation of virulence in mice. J. Gen. Virol. 76: 2757 -2764.

Carey, D.E., Myers, R.M., Reuben, R., Webb, J.K.G. 1969. Japanese encephalitis in South India. A summary of recent knowledge. Indian J. Med. Res. 56: 1340-1352.

Chambers, T.J., Hahn, C.S., Galler, R., and Rice, C.M. 1990. Flavivirus genome organization, expression, and replication. Annu. Rev. Microbiol. 44: 649-688.

Chamber, T.J., Nestorowicz, A., Mason, P.W., and Rice, C.M. 1999. Yellow fever/Japanese encephalitis chimeric viruses. Construction and biological properties. J. Virol. 73:v3095-3101.

Chen, W.R., Tesh, R.B., and Rico-Hesse, R. 1990. Genetic variation of Japanese encephalitis virus in nature. J. gen. Virol. 71: 2915-2922.

Chen, H.W., Pan, C.H., Liau, M.Y., Jou, R., Tsai, C.J., Wu, H.J., Lin, Y.L., and Toa, M.H. 1999. Screening of protective antigen of Japanese encephalitis virus by DNA immunization: a comparative study in conventional viral vaccines. J. Virol. 73: 10137-10145.

Chia, S-C., Leung, P.S.C., Liao, C-P., Huang, J-H., and Lee, S.T. 2001. Fragment of Japanese encephalitis virus envelope protein produced in Escherichia coli protects mice from virus challenge. Microb. Pathol. 31: 9-19.

Garcia, R., and Goldberg, L.J. 1978. University of California Mosquito Control Research. Annu. Rep. 1977, p. 29.

Goldberg, L.J., and Margalit, J. 1977. A bacterial spore demonstrating rapid larvicidal activity against Anopheles serget II, Uranotaenia unquiculata, Culex univitattus, Aedes aegypti, and Culex pipiens. Mosq. News 37, 355.

Goto, A., Hayasake, D., Yoshii, K, Mizutani, T., Kariwa, H., and Takashima, I. 2003. A BHI21 cell culture-adapted tick-borne encephalitis virus mutant is attenuated for neuro-invasiveness. Vaccine 21:4043-4051.

Gould, D.J., Edelman, R., Grossman, R.A., Nisalak, A., and Sullivan, M.F. 1974. Study of Japanese encephalitis virus in Chiangmai Valley, Thailand. IV. Vector studies. Am. J. Epidemiol. 100: 49-56.

Grossman, R.A., Edelman, R., Willhight, M., Pantuwatana, S., and Udomsakdi, S. 1973. Study of Japanese encephalitis virus in Chiangmai Valley, Thailand. III. Human seroepidemiology and inapparent infections. Am. J. Epidemiol. 98: 133 - 149.

Grossman, R.A., Edelman, R., and Gould, D.J. 1974. Study of Japanese encephalitis virus in Chiangmai Valley, Thailand. VI. Summary and conclusions. Am. J. Epidemiol. 100: 69-76.

Hanley, K. A., Lee, J. J., Blaney, J. E., Murphy, B. R., and Whitehead, S. S. 2002. Paired charge-to-alanine mutagenesis of Dengue virus type 4 NSS generates mutants with temperature-sensitive, host range, and mouse attenuation phenotypes. J. Virol. 76: 525-531.

Hasekawa, T., Takehara, Y., and Takahashi, K. 1975.Natural and experimental infections of Japanese tree sparrows with Japanese encephalitis virus. Arch. Virol. 49(4): 373-376.

Heinz FX. 2003. Molecular aspects of TBE virus research. Vaccine 21: S/3-S/10.

Huang, C.Y-H., Butrapet, S., Tsuchiya, K. R., Bharmarapravati, N., Gubler, D.J., and Kinney, R.M. 2003. Dengue 2 PDK-53 virus as a chimeric carrier for tetravalent Dengue vaccine development. J. Virol. 77: 11436-11447. 
Hurlburt, H.S. and Nibly, C.J. 1964. Virus isolations from mosquitoes in Okinawa. J. Med. Entomol. 1: 78-82.

Johnsen, D.O., Edelman, R., Grossman, R.A., Maungman, D., Pomsdhit, J., and Gould, D.J.. 1974. Study of Japanese encephalitis virus in Chiangmai Valley, Thailand. V. Animal infections. Am. J. Epidemiol. 100: 57-68.

Kaur, R., and Sachdeva, G. 2002. Plasmid DNA immunization against Japanese encephalitis virus: immunogenicity of membrane-anchored and secretory envelope protein. $J$. Infect. Dis. 185: 1-12, 17.

Kay, B.H., Fanning, I.D., and Mottram, P. 1989. Rearing temperature influences flavivirus vector competence of mosquitoes. Med. Vet. Entomol. 3(4):415-422.

Kellen WR, Clark TB, Lindegren JE, Ho BC, Rogoff MH and Singer S. Bacillus sphaericus Neide as a pathogen of mosquitoes. J. Invertebr. Pathol. 7: 442, 1965.

Kimura, T., Iwai, K., and Ueba, N. 1973. Difference in plaque size of Japanese encephalitis virus strains on BHK-21 cells and chick embryo cells. Biken J. 16: 57-66.

Kinney, R.M., and Huang, C.Y-H. 2001. Development of new vaccines against Dengue fever and Japanese encephalitis. Intervirology 44: 176-197.

Kono, R., and Kim, K.H. 1969. Comparative epidemiological features of Japanese encephalitis in the Repupublic of Korea, China (Taiwan) and Japan. Bull. Wld. Hlth. Org. 40; 263-277.

Ku, C.C., King, C.C., Lin, C.Y., Hsu, H.C., Chen, L.Y., Yuch, Y.Y., and Chang, G.J.J. 1994. Homologous and heterologous neutralization antibody responses after immunization with Japanese encephalitis vaccine among Taiwan children. J. Med. Virol. 44:122-131.

Kurane, I., and Takasaki, T. 2000. Immunogeneticity and protective efficacy of the current inactivated Japanese encephalitis vaccine against different Japanese encephalitis virus strains. Vaccine 18: 33-35.

Lee, E., Hall, R.A., and Lobigs, M. 2004. Common E protein determinans for attenuation of glycosaminoglycan-binding variants of Japanese encephalitis and West Nile virus. J. Virol. 78: 8271-8280.

Lee, E., and Lobigs, M. 2002. Mechanism of virulence attenuation of glycosaminoglycanbinding variants of Japanese encephalitis virus and Murray Valley encephalitis virus. J. Virol. 76: 4901-4911.

Lin, C.W., and Wu, S-Ch. 2003. A functional determinant on domain III of the Japanese encephalitis virus envelope protein interacted with neutralizing-antibody combining sites. J. Virol. 77: 2600-2603.

Lorroengsil, S., Chen, A., Sallberg, M., and Pantuwatana, S. 2008. Genetic differences of E gene of a Thai strain of Japanese encephalitis virus that determine small plaque size phenotype but not neurovirulence in suckling mice. Southeast Asian J. Trop. Med. Public Health 39:387-393.

Mandl, C.W., Kroschewski, H., Allison, S.L., Kofler, R., Holzmann, H., Meixner, T., and Heinz, F.X. 2001. Adaptation of tick-born encephalitis virus to BHK-21 cells results in the formation of multiple heparan sulfate binding sites in the envelope protein attenuation in vivo. J. Virol. 75: 5627-5637.

Manishia, S., and Vrati, S. 2003. A Japanese encephalitis virus peptide present on Johnson grass mosaic virus-like particles induces virus-neutralizing antibody and protects mice against lethal challenge. J. Virol. 77: 3487-3494. 
Mitamura, T., Kitaoka, M., Watanabe, S., Hosoi, T., Tenjin, S., Seki, D., Nakahata, K. Jo, K., and Shimizu, T. 1939. Weitere Untersuchungen uber die Ubertragung der japanischen Enzephalitis durch Mucken. Trans. Soc. Pathol. Jpn. 29: 92.

Moynihan, J.S., and Howard, C.R. 2001. Recent advances in the development of peptide vaccines for Hepatitis B. Intervirology 44: 65-77.

Myers, P., Yousten, A.A., and Davidson, E.W. 1979. Comparative studies of the mosquitolarval toxin of Bacillus sphaericus SS II-I and 1593. Can. J. Microbiol. 25, 1227.

Ni, H., Chang, G-J J., Xie, H., Trent, D.W., and Barrett A.D.T. 1995. Molecular basis of attenuation of neurovirulence of wild-type Japanese encephalitis virus strain SA 14. J. Gen. Virol. 76: 409-413.

Pan, C.H., Chen, H.W., Huang, HW., and Tao, M.H. 2001. Protective mechanisms induced by a Japanese encephalitis virus vaccine. Requirement for antibody but not CD8 ${ }^{+}$ cytotoxic T-cell response. J. Immunol. 75:11457-11463.

Pantuwatana, S. The prospect of Bti and B sphaericus in mosquito control in Thailand. Israel J. Entomol. 23: 51-57, 1989.

Raymond, B., Johnston, P.R., Nielsen-LeRoux, C., Lereclus, D., and Crickmore, N. 2010. Bacillus thuringiensis: an impotent pathogen? Trends Microbiol. 18: 189-194.

Richman, D.D., Whitley, R.J., and Hayden F.G. 2002. Flaviviruses. In: Monath, T.P., Tsi, T.F., (ed) Clinical Virology $2^{\text {nd }}$ ed. ASM Press, Washington D.C.

Rosen, L., Tesh, R.B., Lien, J.C., and Cross, J.H. 1978. Transovarial transmission of Japanese encephalitis virus by mosquitoes. Science 199: 909-911.

Sangkawibha, N., Nakornsri, S., Rojanasuphot, S., and Ahandarik, S. 1982. Japanese encephalitis in Thailand. J. Dept. Med. Sci. (Thailand) 24: 1-20.

Scherer, W.F., Kitaoka, M., grossberg, S.E., et al. 1959a. Immunology studies of Japanese encephalitis virus in Japan. II. Antibody response following inapparent hunan infection. J. Immunol. 83: 594-604.

Scherer, W.F., Moyer, J.T., Izumi, T., Gresser, I., and McCown, J. 1959b. Ecological studies of Japanese encephalitis in Japan. Parts VI. Swine infection. Am. J. Trop. Med. Hyg. 8: 644-722.

Simasathien, P., Rohitayotshin, S., Nisalak, A., Singharaj, P., Halstead, S.B., and Russel, P.K. 1972. Recovery of Japanese encephalitis virus from wild caught mosquitoes in Thailand. Southeast Asian J. Trop. Med. Public Health 3: 52-54.

Simpson, D.I.H., Bowen, E.T.W., Platt, G.S., Way, H.G., Smith, C.E., Peto, S., Kamath, S., Lim, B.L., and Lim, T.W. 1970. Japanese encephalitis in Sarawak: virus isolation and serology in a Land Dyak village. Trans. Roy. Soc. Trop. Med. Hyg. 64: 503-510.

Singer, S. 1973. Insecticidal activity of recent bacterial isolates and their toxins against mosquito larvae. Nature 244, 110.

Singer, S., and Murphy, D.J. 1976. New insecticidal strains of Bacillus sphaericus useful against Anopheles albimanus larvae. Abstr. 76 th Annu. Meet., American Society of Microbiology, 181).

Sutham, C.M. 1956. Serological studies of encephalitis in Japan. II. Inapparent Infections by Japanese B encephalitis virus. J. Infeect. Dis. 99: 163-169.

Takahashi, M. 1976. The effects of environmental and physiological conditions of Culex tritaeniorhynchus on the pattern of transmission of Japanese encephalitis virus. J. Med. Entomol. 13: 275-284. 
Takahashi, M., and Suzuki, K. 1979. Japanese encephalitis in mosquito salivary gland. Am. J. Trop. Med. Hyg. 28(1):122-135.

Tiroumourougane, S.V., Raghava, P., and Srinivasan, S. 2002. Japanese viral encephalitis. Postgrad. Med. J. 78: 205-215.

Tsai, T. F. 2000. New initiative for the clonal of Japanese encephalitis by vaccination: Minutes of WHO/CVI meeting, Bangkok, Thailand. 13 - 15 October 1998. Vaccine 18: $1-25$.

Undeen, A.H., and Nagel, W.L. 1978. The effect of Bacillus thuringiensis ONR-60A strain (Goldberg) on Simulium larvae in the laboratory. Mosq. News 38, 524.

Wang, S.P. 1964. Japanese encephalitis in Taiwan: A review of recent studies. Bull. Wld. Hlth. Org 30: 297-284.

Watts, D.M., Pantuwatana, S., DeFoliart, G.R., Yuill, T.M., and Thompson, W.H. 1973. Transovarial transmission of La Crosse virus (California Encephalitis group) in the mosquito Aedes triseriatus. Science 82: 1140-1141.

Weiser, J. 1984. A mosquito-virulent Bacillus sphaericus in adult Simulium damnosum from northern Nigeria. Zentralbl. Microbiol. 139: 57.

White, D.O., and Fenner, F., 1984, Medical Virology, Academic Press, INC. (Orlando, U.S.A., $3^{\text {rd }}$ ed, ch 5).

Wickremesinghe, R.S.B., and Mendis, C.L. 1980. Bacillus sphaericus spore from Sri Lanka demonstrating rapid larvicidal activity on Culex quinquefasciatus. Mosq. News 40, 387.

Williams, J.E. and Imlarp, S. 1972. Susceptibility of rodents to Japanese encephalitis virus. Bull. Wld. Hlth. Org. 46: 854-855.

Witthajitsomboon, N., Chen, A., Lorroengsil, S., Sallberg, M., and Pantuwatana, S. 2010. Cloning and expression of envelope protein of Thai genotype I strain KE-093 of Japanese encephalitis virus. Southeast Asian J. Trop. Med. Public Health 41:1359-1367.

Yuill, T.M., Sukhavachana, P., Nisalak, A., and Russel, P.K. 1968. Dengue virus recovery by direct and delayed plaques in LLC-MK 2 cells. Amer. J. Trop. Med. Hyg. 17: 441-448.

Yuill, T.M. 1969. Mosquitoes for drawing blood from small reptiles. Trans. Roy. Soc. Trop. Med. Hyg. 63(3): 407-408. 


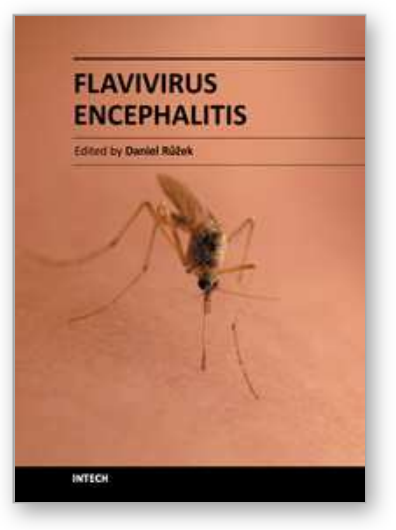

\author{
Flavivirus Encephalitis \\ Edited by Dr. Daniel Ruzek
}

ISBN 978-953-307-669-0

Hard cover, 478 pages

Publisher InTech

Published online 30, September, 2011

Published in print edition September, 2011

Encephalitis is an inflammation of the brain tissue associated with clinical evidence of brain dysfunction. The disease is of high public health importance worldwide due to its high morbidity and mortality. Flaviviruses, such as tick-borne encephalitis virus, Japanese encephalitis virus, Murray Valley encephalitis virus, or St. Louis encephalitis virus, represent important causative agents of encephalitis in humans in various parts of the world. The book Flavivirus Encephalitis provides the most recent information about selected aspects associated with encephalitic flaviviruses. The book contains chapters that cover a wide spectrum of subjects including flavivirus biology, virus-host interactions, role of vectors in disease epidemiology, neurological dengue, and West Nile encephalitis. Special attention is paid to tick-borne encephalitis and Japanese encephalitis viruses. The book uniquely combines up-to-date reviews with cutting-edge original research data, and provides a condensed source of information for clinicians, virologists, pathologists, immunologists, as well as for students of medicine or life sciences.

\title{
How to reference
}

In order to correctly reference this scholarly work, feel free to copy and paste the following:

Somsak Pantuwatana and Matti Sallberg (2011). Prevention and Control of Japanese Encephalitis Viruses: A Challenged Issue, Flavivirus Encephalitis, Dr. Daniel Ruzek (Ed.), ISBN: 978-953-307-669-0, InTech, Available from: http://www.intechopen.com/books/flavivirus-encephalitis/prevention-and-control-of-japaneseencephalitis-viruses-a-challenged-issue

\section{INTECH}

open science | open minds

\section{InTech Europe}

University Campus STeP Ri

Slavka Krautzeka 83/A

51000 Rijeka, Croatia

Phone: +385 (51) 770447

Fax: +385 (51) 686166

www.intechopen.com

\section{InTech China}

Unit 405, Office Block, Hotel Equatorial Shanghai

No.65, Yan An Road (West), Shanghai, 200040, China

中国上海市延安西路65号上海国际贵都大饭店办公楼405单元

Phone: +86-21-62489820

Fax: +86-21-62489821 
(C) 2011 The Author(s). Licensee IntechOpen. This chapter is distributed under the terms of the Creative Commons Attribution-NonCommercialShareAlike-3.0 License, which permits use, distribution and reproduction for non-commercial purposes, provided the original is properly cited and derivative works building on this content are distributed under the same license. 